\title{
QUANTITATIVE COMPARISON OF FIRE DANGER INDEX PERFORMANCE USING FIRE ACTIVITY
}

\author{
K.C. Steenkamp, K.J. Wessels, F. van den Bergh, G.A. McFerren, P.E. Frost, C.W. Lai, D. Swanepoel
}

\author{
CSIR Meraka Institute \\ Meiring Naude Rd, Pretoria, South Africa \\ e-mail: ksteenkamp@csir.co.za
}

\section{INTRODUCTION}

Fire danger indices (FDI) describe the conditions that influence ease of ignition, rate of spread and the impact caused by fires [1]. It is used to assess the safety of prescribed burning activities, to improve real-time fire fighting preparedness and in logistic planning of fire fighting resources $[2,3]$.

Different indices are being used for specific areas while some FDIs, e.g. the Canadian Fire Weather Index (FWI), are now being applied globally in the Global Wildfire Early Warning System [1]. The choice of FDI is often made subjectively due to the lack of objective comparison methods. Evaluation of the performance of indices is a difficult task due to the ambiguous concept of fire risk. Fire risk (or potential) cannot be measured directly but can only be inferred by measuring the components of which the index consists, such as temperature, relative humidity, rainfall and wind speed $[4,5]$. This contrasts with fire behavior models in which physical parameters such as flame length or rate of spread can be physically measured or modeled. Fire danger indices are not designed to describe the characteristics of a fire but rather the potential of a fire taking place in an area of interest [5].

Several different approaches have been taken in evaluating FDIs, but $[5,6]$ found that fire activity is a useful concept based on the assumption that higher FDI values corresponds with increased fire occurrences. Fire activity can furthermore be assessed using remotely sensed data such as active fire detections and burned area maps as a proxy of historical fire activity. In a study by [6] fire activity collected from the field were evaluated with the Normalized Difference
Vegetation Index (NDVI), Normalized Difference Water Index (NDWI) and Keetch-Byram Drought Index (KBDI) using performance measures extracted from a binary logistic model. It was successfully demonstrated that the vegetation based NDWI can be used effectively as a fire risk indicator. In a paper by [5] a quick, objective and quantitative guideline for selecting an appropriate FDI for a specific areas was suggested by ranking an number if measures in terms of performance. These measures included logistic regression, percentile shift analyses and the Mahalanobis distance.

A similar approach is used in this study to identify the most suitable FDI for application in South Africa. The indices in the comparison includes the Lowveld Fire Danger Index (LFDI), used by the South African fire management community, the internationally used FWI, the McArthur Forest Fire Danger Index (FFDI) and the McArthur Grassland Fire Danger Index (GFDI).

In this study historical fire activity from remotely sensed data are compared with various FDIs to identify which index has the strongest statistical relationship with fire occurrences and therefore the highest forecasting potential for fires in the future.

\section{METHODOLOGY}

Meteorological data on temperature, relative humidity, rainfall and wind speed were obtained from the South African Weather Services (SAWS) for calculation of the FDIs. This gridded data was modeled with the Unified Numerical Weather Prediction (NWP) model at a $11 \mathrm{~km}$ cell size and data for the time period June 2007 to October 2010 were used. Unfortunately NWP 
data prior to 2007 could not be used due to incomparability with the previously used Eta NWP model.

Historical fire activity was determined by using burned area data as well as active fire detections from the MODIS sensors onboard the Terra and Aqua satellite platforms. In preparation of fire activity per $11 \mathrm{~km}$ meteorological cell, individual fires were calculated by the integrating the $500 \mathrm{~m} \mathrm{MCD} 45 \mathrm{~A}$ and MCD64A1 burned area data products with the $1 \mathrm{~km}$ MOD14A1 and MYD14A1 active fire products. This was done by considering the proximity and date of neighboring burned area pixels and their association with active fire detections. If a neighboring burned area pixel was connected to another burned pixel within a two-day time period, the two pixels were considered as part of the same fire. Individual fires were subsequently aggregated into $11 \mathrm{~km}$ cells, comparable in size to the meteorological data.

Given that the data is in a binary form, fire activity is expressed as a fire-day in which a value of 1 if allocated to a cell if one or more fires occurs and 0 otherwise [5]. In this study fire activity was defined in terms of (i) a fire-day (ii) a multiple fire-day when more than 5 fires occurred and (iii) a large fire-day when more than 4 burned area pixels (100 ha) were recorded.

According to [7]more than 10 events per variable is required in logistic regression to avoid bias in both positive and negative directions. A threshold of 20 large fire events per cell were used in this study to avoid bias and have appropriate frequency distributions for percentile analyses. However, if the 20 fire events per cell threshold is taken into account, very few multiple fire-days are present in the dataset and a meaningful logistic regression fit on this fire activity type cannot be obtained. Therefore only fire-days and large fire-days were further used as an indication of fire activity. The 20 large fire event threshold per cell resulted in reducing the data set from 22700 to 3680 cells.

It is important to note the unique spatial approach of this study in which the performance of each FDI is ranked per individual cell, which provides a regional analyses of the effectiveness of the FDIs versus a point based comparison at weather stations.
The ranking of the FDIs were based on the total rank obtained from assessing measures from the logistic regression, percentile shift analyses and the Bhattacharyya coefficient. Logistic regression was used to determine the probability that fire will take place on any particular day, as a function of FDI values. The FDI were defined as the independent variable and fire-day and large fire-day as the response variables [5]. Metrics used for the ranking of the FDIs were the $\mathrm{R}^{2}$ and the range of predicted values obtained from the logistic model.

In percentile shift analyses the $25^{\text {th }}, 50^{\text {th }}$ and $90^{\text {th }}$ percentile values of all-days were compared with the percentile values of fire-days and large fire-days. A shift towards higher FDI values of days on which fire occurred, indicates that increased historical fire activity relates to higher FDI values. Empirical cumulative distribution functions were employed to calculate the distances between the frequency distributions of alldays versus fire activity days. The largest distances between the frequency distributions, indicating higher correlation of FDIs with fire activity, were given a ranking of one, with shorter distances being ranked with higher values.

It was decided to use Bhatthacharyya coefficient to measure the amount of overlap between the distributions of no fire-days and fire. In this case a shorter distance indicates an increased relationship between the specific FDI and fire activity. The individual ranking of $\mathrm{i}$ ) the $\mathrm{R}^{2}$ obtained from logistic regression ii) the range of the predicted values from the logistic model iii) percentile shifts and iv) Bhatthacharyya coefficient were summarized in a total ranking with the lowest value as the best ranking FDI.

\section{RESULTS}

The overall ranking of the cells according to all four measures are summarized in Table 1 , normalized to percentages. The FWI ranks as the highest ranking FDI at $90.32 \%$, followed by the LFDI in second place with $54.75 \%$. Although ties occur between the LFDI and FFDI in the third position with $33.42 \%$ and $32.28 \%$ respectively, the FFDI is placed thirdly because of the high ranking of LFDI in the second position. The GDFI is ranked last with a $45.73 \%$ in the fourth position. 
Table 1: Overall ranks of FDIs expressed in percentages

\begin{tabular}{|l|r|r|r|r|}
\hline & $\begin{array}{l}\text { LFDI } \\
\text { (\%) }\end{array}$ & \multicolumn{1}{|l|}{$\begin{array}{l}\text { FWI } \\
\text { (\%) }\end{array}$} & \multicolumn{1}{l|}{$\begin{array}{l}\text { GFDI } \\
\text { (\%) }\end{array}$} & \multicolumn{1}{l|}{$\begin{array}{l}\text { FFDI } \\
\text { (\%) }\end{array}$} \\
\hline Rank 1 & 6.46 & 90.32 & 2.55 & 5.48 \\
\hline Rank 2 & 54.75 & 5.64 & 21.4 & 30.1 \\
\hline Rank 3 & 33.42 & 2.71 & 30.31 & 32.28 \\
\hline Rank 4 & 5.37 & 1.33 & 45.73 & 32.15 \\
\hline
\end{tabular}

The spatial extent of the $11 \mathrm{~km}$ cells in which the FWI was ranked first is shown in Fig 1. The white areas in the western parts of south Africa are not associated with either burned area pixels or active fire records due to a lack of fuel and low rainfall. In the eastern parts of the country the lack of ranked cells is caused by the 20 large fire event threshold for each meteorological cell.

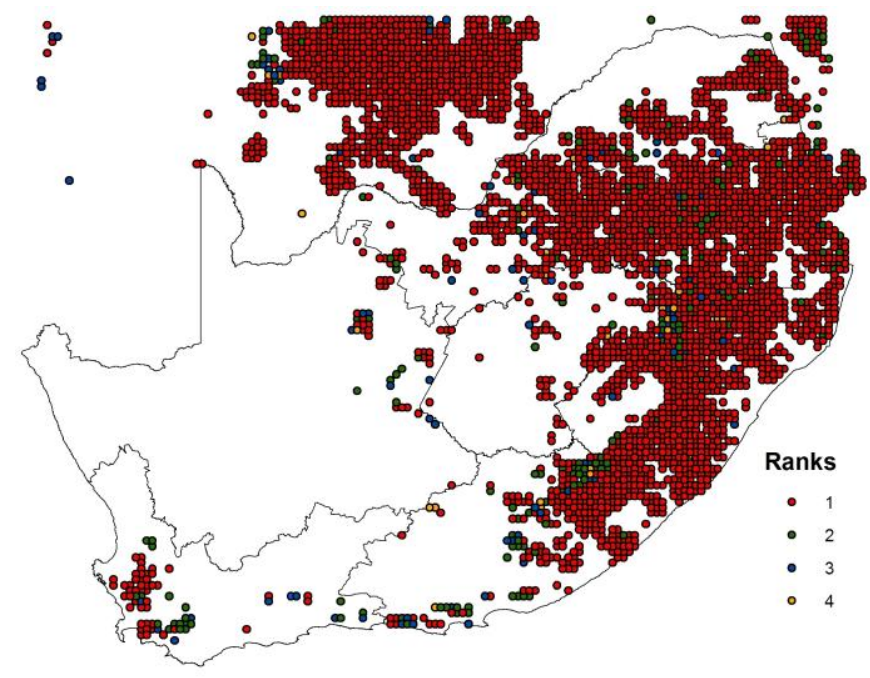

Fig 1: The Fire Weather Index (FWI) showed according to ranks.

The spatial extent of the FWI (Fig 1) ranked first in most of the country indicates its strong relationship with fire activity. Fig 1 also illustrates results in Table 1 in which less than $15 \%$ of the remaining FDIs was ranked first.

The difference between FWI and LFDI in terms of the $\mathrm{R}^{2}$ value form the logistic regression is shown in Fig 2 whit the LFDI $\mathrm{R}^{2}$ values peaking much lower than the FWI values.

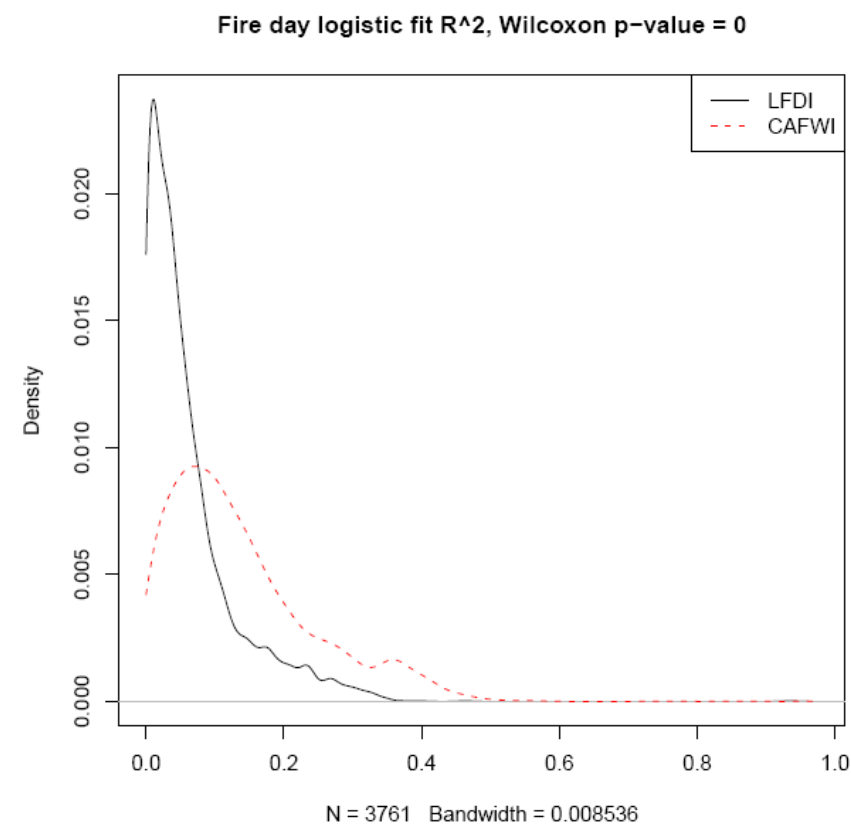

Fig 2: $\mathrm{R}^{2}$ results from the fire-day logistic model for FWI and LFDI.

(need to comment on low $R 2$ for logistic regression)

\section{DISCUSSION}

Most of the fires occur in the eastern parts of South Africa due to sufficient fuel and dry conditions in winter in the summer rainfall region. The south western Cape is a winter rainfall region with fires occurring in Fynbos vegetation.

It was found that the FWI performed the best in most part of South Africa. However the usage of the LFDI model is entrenched in local communities and there is a clear understanding of resources required to suppress fires based on the LFDI color coding. It is therefore suggested to historical use of the LFDI model is used in conjunction with the FWI.

\section{REFERENCES}

[1] W. J. de Groot, et al., "Developing a global early warning system for wildland fire," Forest Ecology and Management, vol. 234, pp. S10-S10, 2006. 
[2] A. P. Dimitrakopoulos, et al., "Evaluation of the Canadian fire weather index system in an eastern Mediterranean environment," Meteorological Applications, vol. 18, pp. 83-93, 2011.

[3] A. J. Dowdy, et al., "Index sensitivity analysis applied to the Canadian Forest Fire Weather Index and the McArthur Forest Fire Danger Index," Meteorological Applications, vol. 17, pp. 298-312, 2010.

[4] J. J. Sharples, et al., "A simple index for assessing fire danger rating," Environmental Modelling \& Software, vol. 24, pp. 764-774, 2009.

[5] P. L. Andrews, et al., "Evaluation of fire danger rating indexes using logistic regression and percentile analysis," International Journal of Wildland Fire, vol. 12, pp. 213226, 2003.

[6] J. Verbesselt, et al., "Evaluating satellite and climate data-derived indices as fire risk indicators in savanna ecosystems," Geoscience and Remote Sensing, IEEE Transactions on, vol. 44, pp. 1622-1632, 2006.

[7] P. Peduzzi, et al., "A simulation study of the number of events per variable in logistic regression analysis," Journal of Clinical Epidemiology, vol. 49, pp. 13731379, 1996. 